пыт применения метилпреднизолона ацепоната в терапии опухолевидной красной волчанки

Л.П. Котрехова, А.А. Вашкевич

ГБОУ ВПО «Северо-Западный государственный медицинский университет им. И.И. Мечникова» 191015, Санкт-Петербург, ул. Кирочная, д. 41

Опухолевидная красная волчанка относится к редко встречающимся кожным формам красной волчанки. В настоящее время в мире описано около 250 случаев опухолевидной красной волчанки. Специфические клинические признаки данного дерматоза — появление кольцевидных или дугообразных уртикароподобных высыпаний. Как правило, появлению высыпаний предшествует ультрасиолетовое облучение. Применение глюкокортикостероидных препаратов местного действия, относящихся к классам сильных и сверхсильных стероидов, - первая линия терапии опухолевидной красной волчанки. Приводится случай успешного лечения метилпреднизолона ацепонатом (мазь Адвантан) опухолевидной волчанки у больной 56 лет.

Ключевые слова: опухолевидная красная волчанка, метилпреднизолона ацепонат, мазь Адвантан.

Контактная информация: zurupalubov@inbox.ru. Вестник дерматологии и венерологии 2015; (4): 132_136.

\title{
An experience of using methylprednisolone aceponate in the therapy of lupus erythematosus tumidus
}

L.P. Kotrekhova, A.A. Vashkevich

State budget institution of higher education "North-Western State Medical University named after I.I. Mechnikov" under the Ministry of Public Health of the Russian Federation

Kirochnaya str., 41, St. Petersburg, 191015, Russia

Lupus erythematosus tumidus is a rare skin form of lupus erythematosus. About 250 cases of lupus erythematosus tumidus have been described in the world by now. A specific clinical sign of this dermatosis is the appearance of annular or arcuate urticaria-like rash. As a rule, the appearance of the rash is preceded by ultraviolet irradiation. The administration of glucocorticosteroid drugs of local action belonging to classes of potent and very potent steroids is the first-line therapy for lupus erythematosus tumidus. The authors describe a case of the successful treatment of lupus erythematosus tumidus with methylprednisolone aceponate (Advantan ointment) in a female patient aged 56.

Key words: lupus erythematosus tumidus, methylprednisolone aceponate, Advantan ointment.

Corresponding author: zurupalubov@inbox.ru. Vestnik Dermatologii i Venerologii 2015; 4: 132—136. 
Красная волчанка относится к диффузным заболеваниям соединительной ткани, в основе патогенеза которой лежит хроническое аутоиммунное воспаление. Красная волчанка характеризуется разнообразием клинических проявлений и вариабельностью эволюционных изменений. Кожа часто становится первым органом, который вовлекается в патологический процесс при разных вариантах течения системной красной волчанки. В некоторых случаях проявления красной волчанки ограничиваются только кожным покровом - кожная красная волчанка. В течение последних нескольких десятилетий активно изучались учеными всего мира механизмы развития кожной красной волчанки. Результатом этих исследований стало выявление множества кожных фрорм красной волчанки, описание их клинических и фотобиологических особенностей, гистологических и иммунопатологических изменений, а также отклонений в результатах лабораторных анализов.

Одной из таких относительно редко встречающихся кожных фрорм красной волчанки является опухолевидная красная волчанка. Характер клинических проявлений, особенность течения, редкая встречаемость опухолевидной красной волчанки, а также недостаточная осведомленность дерматологов об этой нозологической фрорме приводят к ее поздней диагностике и проведению нерациональной терапии. Применение топических кортикостероидов является частью стандартной наружной терапии кожных фрорм красной волчанки, в том числе и опухолевидной. В качестве монотерапии или в комбинации с системными противовоспалительными средствами топические глюкокортикостероиды высокоэффрективны в разрешении основных симптомов опухолевидной красной волчанки. Для достижения максимально выраженного эфффекта необходимо использовать сильные и сверхсильные топические глюкокортикостероиды, такие как триамцинолона ацетонид, бетаметазона дипропионат и клобетазола пропионат. Однако из-за необходимости их длительного применения при красной волчанке возрастает риск развития нежелательных явлений: атрофии, телеангиэктазий, стероидного дерматита, фолликулитов и т.д., особенно при локализации высыпаний на коже лица. Применение метилпреднизолона ацепоната благодаря высокому профилю безопасности и выраженному противовоспалительному эфффекту позволяет избежать развития нежелательных явлений при длительной терапии кожных форм красной волчанки. Приводим пример успешного применения мази Адвантан, действующим веществом которого является метилпреднизолона ацепонат, в комплексной терапии опухолевидной красной волчанки.

Пациентка К., 56 лет, обратилась в клинику с жалобами на красные, возвышающиеся высыпания на коже спины в области поясничного отдела позвоночника.
Со слов пациентки, высыпания появились за 1,5 мес. до обращения в консультативно-диагностическое отделение СЗГМУ им. И.И. Мечникова. Появление высыпаний никакими субъективными ощущениями не сопровождалось. Ранее пациентка обращалась за медицинской помощью к дерматологу и аллергологу. Высыпания обоими специалистами были расценены как проявления острой крапивницы. Рекомендовано принимать антигистаминный препарат (дезлоратадин 5 мг/сут) и наружно смазывать очаг френистил гелем и цинковой мазью. Эффректа от проведенной терапии не было. При сборе анамнеза обратил на себя внимание факт посещения пациенткой солярия за несколько недель до того, как она обнаружила высыпания на спине. Из анамнеза жизни известно, что в 1979 г. пациентка перенесла вирусный гепатит А, в 2009 г. пациентке была проведена аппендэктомия. Простудными заболеваниями болела редко, наличие каких-либо соматических заболеваний отрицала. Гинекологический анамнез без особенностей, беременностей -2 , родов - 2 . Менопауза с 49 лет. Аллергологический анамнез без особенностей: наличие каких-либо аллергических реакций в момент осмотра отрицала.

При объективном осмотре на коже поясничной области выявлено 2 уртикароподобных очага кольцевидной формы. Больший очаг размером 5,5 × 6 см, меньший диаметром 3 см. Края очагов отечны, приподняты, в центре очага имелось некоторое уплощение. По периферии очагов окраска была интенсивно красного цвета, в центре - цвета здоровой кожи. Шелушение на поверхности высыпаний отсутствовало, болезненных или каких-либо других ощущений при пальпации элементов не возникло (рис. 1).

Учитывая длительность существования уртикароподобных высыпаний, связь их появления с ультрафриолетовым излучением, пациентке были назначены скрининговые анализы для диагностики диффузных заболеваний соединительной ткани и проведение диагностической биопсии кожи.

В результате проведенного обследования было выявлено только повышение уровня антител к экстрагируемым ядерным антигенам анти-Ro/SSA (в титре >1:160), тогда как другие изменения, характерные для красной волчанки, отсутствовали. Не выявлено каких-либо изменений со стороны клинического анализа крови, общего анализа мочи, также отсутствовало повышение уровня С-реактивного белка, наличие антинуклеарного фрактора не обнаружено. Гистологическое исследование кожи (окраска гематоксилином и эозином) показало отсутствие патологических изменений в эпидермисе. В верхней части дермы наблюдался умеренно выраженный отек. В дерме располагались плотные очаговые поверхностные и глубокие лимфоцитарные периваскулярные и периаднексальные инфильтраты. При окраске препарата альциановым синим выявлено значительное отложение муцина 


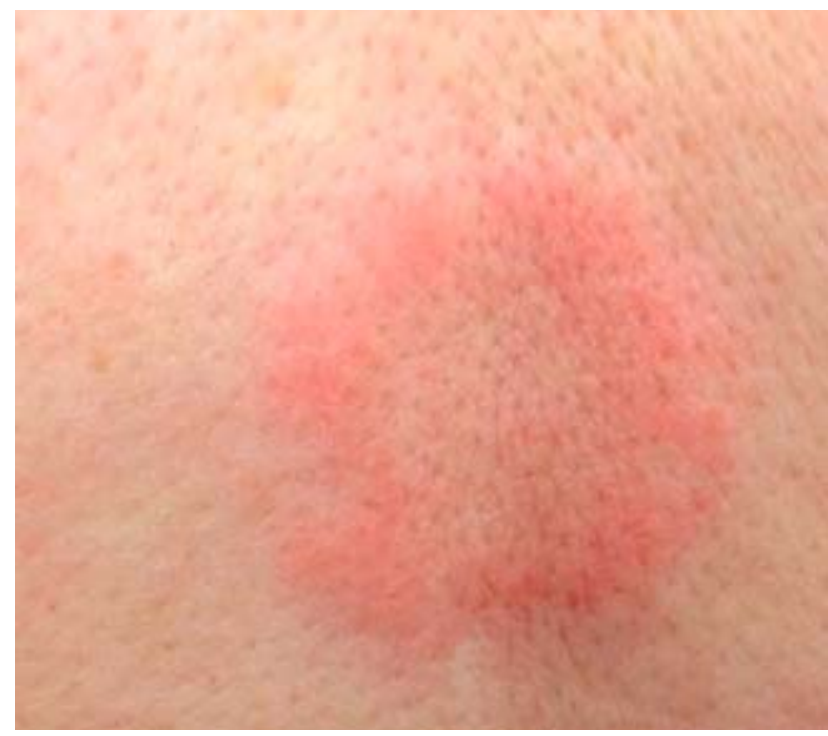

Кольцевидный уртикароподобный очаг на

Рис. 1. поясничной области у больной опухолевидной красной волчанкой

в сетчатом слое дермы. Тест «волчаночной полоски» был отрицательным.

На основании клинической картины, гистологических изменений, анамнестических данных о связи появления высыпаний с УФ-облучением, а также выявления анти-Ro/SSA больной был поставлен диагноз опухолевидной красной волчанки. После верифрикации диагноза пациентке назначена комбинированная терапия гидроксихлорохина сульфатом (плаквенилом) в дозе 200 мг 2 раза в сутки и для наружного применения метилпреднизолона ацепонат (мазь Адвантан) 1 раз в день. Через 2 нед. после начала терапии отмечалась фррагментация очага, его оседание, побледнение его окраски (рис. 2). Полное разрешение высыпаний было отмечено через 1,5 мес. от начала лечения (рис. 3). Нежелательных явлений, вызванных системной терапией или местной терапией, у пациентки не развилось.

\section{Обсуждение}

Термин «опухолевидная красная волчанка» Lupus Erythematosus Tumidus был впервые предложен немецким дерматологом E. Hoffmann в 1909 г. на заседании Берлинского дерматологического общества $[1,2]$. Более детально это редкая разновидность хронической кожной красной волчанки была описана лишь в 1930 г. M. Gougerot и R. Bournier [2]. В последующие годы данной форме уделялось мало внимания, было опубликовано описание лишь нескольких случаев

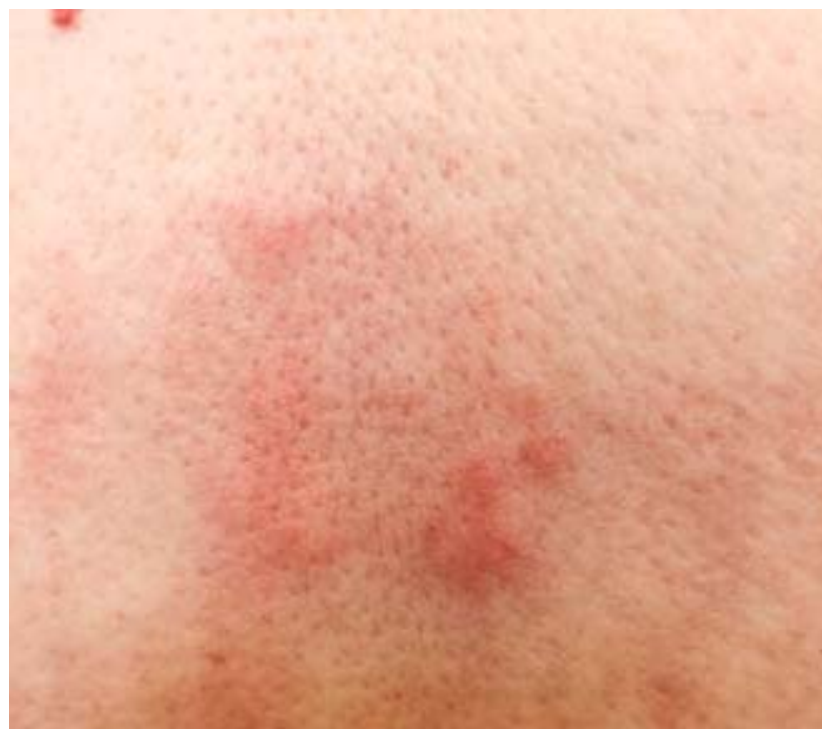

Разрешающийся очаг опухолевидной крас-

Рис. 2. ной волчанки на фоне двухнедельного применения метилпреднизолона ацепоната (мазь Адвантан) один раз в день

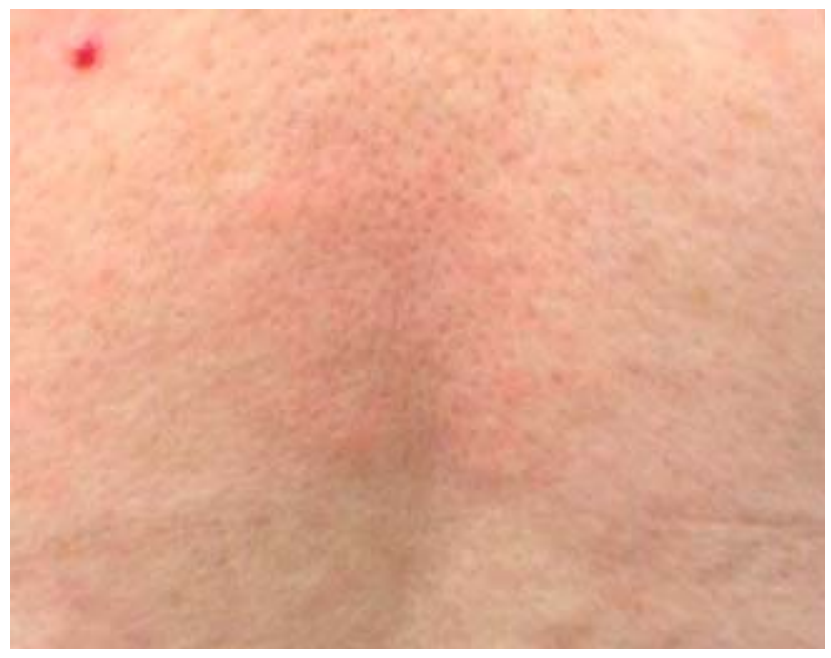

Полное разрешение проявлений опухоле-

Рис. 3. видной красной волчанки после применения метилпреднизолона ацепоната (мазь Адвантан) один раз в день в течение 1,5 мес.

[3-8]. Опухолевидная красная волчанка изначально не рассматривалась как самостоятельная фрорма хронической кожной красной волчанки [9] и не была включена в классификацию кожных проявлений, ассоциированных с красной волчанкой, предложенной 
J. Gilliam в 70-е годы прошлого столетия [10]. Однако в последние десятилетия рядом авторов были предприняты усилия по изучению и описанию специфических клинических и гистопатологических особенностей опухолевидной красной волчанки для того, чтобы выделить диффреренциально-диагностические критерии, отличающие ее от других форм красной волчанки. В настоящее время опухолевидная красная волчанка рассматривается как подтип дискоидной красной волчанки с клиническими, прогностическими и гистопатологическими особенностями. Ряд авторов высказывают предположение, что опухолевидная красная волчанка, ретикулярный эритематозный муциноз, папулонодулярный муциноз и лимфоцитарная инфильтрация Джесснера - Канофа представляют собой тождественные нозологические формы [11-15].

Частота встречаемости опухолевидной красной волчанки выше, чем считалось несколько десятилетий назад, и хотя нет полных данных о распространенности, на настоящий момент в литературе описано примерно 250 случаев, большинство этих наблюдений были опубликованы в течение последних 10 лет [9]. Однако истинная распространенность неизвестна [16, 17]. В отличие от других форм красной волчанки опухолевидная красная волчанка встречается у мужчин и женщин примерно в равной пропорции $[1,9,16,18]$. Средний возраст начала заболевания аналогичен возрасту начала дискоидной красной волчанки $[9,18]$. Следует отметить, что имеются также сообщения о случаях заболевания у детей с такими же клиническими и гистопатологическими особенностями, как и у взрослых пациентов [19].

В литературе содержатся противоречивые сведения относительно возможности сосуществования данной фрормы заболевания одновременно с системной красной волчанкой или с другими формами хронической кожной красной волчанки $[18,20]$. Имеются отдельные сообщения о больных с одновременными высыпаниями, характерными как для опухолевидной волчанки, так и для дискоидной [3, 7, 17, 21-23]. Пациенты с опухолевидной волчанкой, как правило, имеют только кожные проявления, однако возможно наличие признаков системного заболевания [3, 21, 22]. Появление высыпаний почти всегда связано с пребыванием на солнце, в основном весной и летом. Для опухолевидной красной волчанки характерно появление высыпаний после латентного периода, который колеблется от 24 ч до нескольких недель, как это было в представленном нами случае [9, 18, 24].

Клиническая картина характеризуется высыпаниями, преимущественно на открытых участках, подверженных солнечному воздействию: лицо, верхняя часть спины, в области шеи, туловища и верхних конечностей, крайне редко на коже нижних конечностей $[18,21,23,25]$, в виде уртикароподобных эритематозных папул, бляшек, которые в результате слияния могут образовывать кольцевидные или дугообразные элементы [26]. Клиническими особенностями, отличающими эту фрорму от других кожных фрорм красной волчанки, являются отсутствие шелушения, фолликулярного кератоза или атрофии, отсутствие рубцов или гипопигментации после разрешения. Высыпания могут разрешаться спонтанно, а затем рецидивировать на том же месте [2, 17, 25, 27].

Гистологические изменения обычно представлены очаговыми поверхностными и глубокими периваскулярными и периаднексальными лимфоцитарными инфрильтратами, обильным интерстициальным отложением муцина. В некоторых случаях может наблюдаться и поверхностный дермальный отек. Отличительной чертой от других форм хронической кожной волчанки являются минимальные эпидермальные изменения или их полное отсутствие [9, 16, 28]. Тест «волчаночной полоски» - реакция прямой иммунофлюоресценции, обычно отрицательный [9, 16, 18, 21, 28, 29]. Иммуногистохимические исследования продемонстрировали преобладание СДЗ и СД4 клеток с соотношением примерно 3:1 и низким процентом СД8 [9, 23]. Серологические показатели при опухолевидной красной волчанке не отличаются от таковых при других формах хронической кожной волчанки $[1,9,16,18]$.

Терапией первой линии являются противомалярийные препараты в комбинации с топическими стероидами. Пациентам следует избегать инсоляции и необходимо пользоваться фотозащитными препаратами [14, 16, 18, 29, 30]. К выбору топических стероидов следует подходить особенно внимательно при локализации высыпаний на лице. Галогенизированные глюкокортикостероиды и глюкокортикостероиды, относящиеся к группам сильных и сверхсильных, при локализации высыпаний на лице в обычной практике не применяются из-за высокого риска развития атрофии, телеангиэктазий, стероидного дерматита. Только при красной волчанке делается исключение, так как ожидаемая польза превышает возможный вред от применения сильных и сверхсильных топических глюкокортикостероидных препаратов. Строение молекулы метилпреднизолона ацепоната (Адвантана) с двумя эфирными группами в положениях С17 и С21 (двойная эстерификация) обеспечивает высокую липофильность препарата и выраженное противовоспалительное действие, при этом атрофрогенный потенциал низкий. В большинстве случаев нет системных побочных эффректов. После проникновения в кожу метилпреднизолона ацепонат гидролизируется эстеразами до его активного метаболита метилпреднизолона 17-пропионата, который обладает большим сродством к кортикостероидному рецептору [31]. При лечении опухолевидной фрормы красной волчанки более всего подходит лекарственная форма препарата в виде мази или жирной мази из-за своей лучшей проникающей способности и силы противовоспалительного действия. 


\section{Заключение}

Приведенный нами клинический опыт успешного применения метилпреднизолона ацепоната свидетельствует о его высокой эфффективности в терапии опухолевидной красной волчанки и позволяет сделать вывод о возможности более широкого применения Адвантана в терапии кожных фрорм красной волчанки.

\section{Литература}

1. Kuhn A., Bein D., Bonsmann G. The 100th anniversary of lupus erythematosus tumidus Autoimmun Rev 2009; 8 (6): 439_-532.

2. Gougerot M., Bournier R. Lupus erythemateux "tumidus". Bull Soc Fr Derm Syph 1930; 37: 1291-1292.

3. Stead J., Headley C., loffreda M. et al. Coexistence of tumid lupus erythematosus with systemic lupus erythematosus and discoid lupus erythematosus: a report of 2 cases. J Clin Rheumatol 2008; 14 (6): 338-341.

4. Manok M. Lupus erythematosus tumidus. Hautarzt 1957; 8: 373-374.

5. Rock H. Erythematodes tumidus; a case history with reference to the problem of erythematodic Iymphocytoma Hautarzt 1954; 5: 422—423.

6. Vilanova $X$. The profundus and tumidus forms of lupus erythematosus; report of a case and comments. Rev Clin Esp 1950; 36: 388-393.

7. Casala A.M., Bianchi C., Bianchi O. Lupus erythematosus tumidus (lymphocytic infiltration of the skin) and chronic lupus erythematosus associated in the same patient. Immunofluorescent study. Bull Soc Fr Dermatol Syphiligr 1971; 78: 256-258.

8. Mosquera J.C., Torre C., Cruces M.J. Gougerot's lupus erythematosus tumidus. Med Cutan Ibero Lat Am 1984; 12: 425—429.

9. Schmitt V., Meuth A.M., Amler S. et al. Lupus erythematosus tumidus is a separate subtype of cutaneous lupus erythematosus. Br J Dermatol 2010; 162: 64-73.

10. Gilliam J.N., Sontheimer R.D. Distinctive cutaneous subsets in the spectrum of lupus erythematosus. J Am Acad Dermatol 1981; 4: 471—475.

11. Kozlovskaya V.V., Tikhonovskaya I.V., Kozlovsky V.I. Peculiarities of clinical picture and differential diagnostics of tumour-like lupus erythematosus. Klinicheskaya Meditsina 2013; (4): 65-69. [Козловская В.В., Тихоновская И.В., Козловский В.И. Особенности клиники и дифрференциального диагноза опухолевидной волчанки. Клин Мед 2013; (4): 65—69.]
12. Antonova O.V., Trofimov P.N. Belousova I.E. Samtsov A.V. Reticular erythematous mucinosis. Vestn Dermatol Venerol 2014; (5): 96—99. [Антонова О.В. Тросиммов П.Н., Белоусова И.Э., Самцов А.В. Ретикулярный эритематозный муциноз. Вестн дерматол венерол 2014; (5): 96-99.]

13. Obermoser G., Sontheimer R.D., Zelger B. Overview of common, rare and atypical manifestations of cutaneous lupus erythematosus and histopathological correlates. Lupus 2010; 19 (9): 1050-1070.

14. Remy-Leroux V., Leonard F., Lambert D. Comparison of histopathologic-clinical characteristics of Jessner's lymphocytic infiltration of the skin and lupus erythematosus tumidus: multicenter study of 46 cases. J Am Acad Dermatol 2008; 58 (2): 217-23.

15. Bonczkowitz M., Weyers W. Differentiation of lupus erythematosus and lymphocytic infiltration. Verh Dtsch Ges Pathol. 1996; 80: 235—240.

16. Vieira V., Del Pozo J., Yebra-Pimentel M.T. et al. Lupus erythematosus tumidus: a series of 26 cases. Int J Dermatol 2006; 45: 512—517.

17. Lehrhoff S., Tzu J., Patel R. et al. Lupus erythematosus tumidus with discoid lupus erythematosus-induced alopecia of the scalp. Dermatol Online J 2011; 17 (10): 24.

18. Kuhn A., Richter-Hintz D., Oslislo C. et al. Lupus erythematosus tumidus - a neglected subset of cutaneous lupus erythematosus: report of 40 cases. Arch Dermatol 2000; 136: 1033-1041.

19. Sonntag M., Lehmann P., Megahed M. et al. Lupus erythematosus tumidus in childhood. Report of 3 patients. Dermatology 2003; 207: 188-192.

20. Pramatarov K.D. Chronic cutaneous lupus erythematosus - clinical spectrum. Clin Dermatol 2004; 22: 113-120.

21. Ruiz H., Sanchez J.L. Tumid lupus erythematosus. Am J Dermatopathol 1999; 21 (4): 356-360.
22. Jolly M., Laumann A.E., Shea C.R., Utset T.0. Lupus erythematosus tumidus in systemic lupus erythematosus: novel association and possible role of early treatment in prevention of discoid lupus erythematosus. Lupus 2004; 13 (1): 64—69.

23. Alexiades-Armenakas M.R., Baldassano M., Bince B. et al. Tumid lupus erythematosus: criteria for classification with immunohistochemical analysis. Arthritis Rheum 2003; 49: 494—500.

24. Kuhn A., Sonntag M., Richter-Hintz D. et al. Phototesting in lupus erythematosus: a 15-year experience. J Am Acad Dermatol. 2001; 45: 86—95.

25. Dekle C.L., Mannes K.D., Davis L.S., Sangueza 0.P. Lupus tumidus. J Am Acad Dermatol 1999; 41: 250-253.

26. Mascaro J.M., Herrero C., Hausmann G. Uncommon cutaneous manifestations of lupus erythematosus. Lupus 1997; 6 (2): 122-131.

27. Samtsov A.V., Barbinov V.V., Belousova I.E. Tumor-like lupus erythematosus. Vestn Dermatol Venerol 2008; (3): 75-76. [Самцов A.B., Барбинов В.В., Белоусова И.Э. Опухолевидная красная волчанка. Вестн дерматол венерол 2008; (3): 75-76.]

28. Kuhn A., Sonntag M., Ruzicka T. et al. Histopathologic findings in lupus erythematosus tumidus: review of 80 patients. J Am Acad Dermatol 2003; 48: 901-908.

29. Cozzani E., Christana K., Rongioletti F. et al. Lupus erythematosus tumidus: clinical, histopathological and serological aspects and therapy response of 21 patients. Eur J Dermatol 2010; 20: 797—801.

30. Choonhakarn C., Poonsriaram A., Chaivoramukul J. Lupus erythematosus tumidus. Int J Dermatol 2004; 43 (11): 815-818.

31. Chikin V.V. Topical methylprednisolone aceponate and dexpanthenol in the treatment of patients with atopic dermatitis. Vestn Dermatol Venerol 2014; (5): 112—117. [Чикин В.В. Метилпреднизолона ацепонат и декспантенол в топической терапии больных атопическим дерматитом. Вестн дерматол венерол 2014; (5): 112—117.]

об авторах:

Л.П. Котрехова — к.м.Н., доцент кафедры дерматовенерологии ГБоУ ВПО СЗГМУ им. И.И. Мечникова, Санкт-Петербург

А.А. Вашкевич — к.м.Н., доцент кафедры дерматовенерологии ГБоУ ВПо СЗГМУ им. И.И. Мечникова, Санкт-Петербург

\section{Конфликт интересов}

Авторы заявляют об отсутствии потенциального конфликта интересов, требующего раскрытия в данной статье 